\title{
$\mathrm{SRR}$ 과 CSRR을 이용한 삼중 대역 차단 초광대역 안테나
}

\section{SRR and CSRR Loaded UWB Antenna with Tri-Band Notch Capability}

\author{
유 민 영 · 임 성 준 \\ Minyeong Yoo $\cdot$ Sungjoon Lim \\ 요 약
}

본 논문에서는 삼중 대역을 차단하는 기능을 가진 초광대역(UWB) 안테나를 제안하고자 한다. 본 안테나는 WiMAX의 3.3 3.7 GHz 대역, WLAN IEEE $802.11 \mathrm{a} / \mathrm{n}$ 의 $5.15 \sim 5.825 \mathrm{GHz}$ 대역, ITU의 $8.025 \sim 8.4 \mathrm{GHz}$ 대역을 차단하는 능력을 갖고 있다. 대역 차단 기능은 SRR과 CSRR만으로 이루어졌으며, 특히 방사체 하단 부분에 위치 한 SRR을 이용하여 WiMAX 대역을 차단하였고, 방사체 상의 CSRR을 통해 WLAN 대역을 차단하였으며, CPW 급전부에 있는 접지면의 CSRR을 통해 ITU 대역을 차단하였다. 설계 및 제작된 안테나는 시뮬레이션과 측정 결과를 통해 본 논문에서 제안하는 안테나의 성능을 입증하고자 한다.

\section{Abstract}

In this paper, a novel ultra wide band(UWB) antenna with tri-band notch capability is proposed. The proposed antenna can reject WiMAX(3.3 3.7 GHz), WLAN IEEE $802.11 \mathrm{a} / \mathrm{n}(5.15 \sim 5.825 \mathrm{GHz})$, and ITU(8.025 8.4 GHz) bands. Band rejection capability is achieved only split ring resonators(SRRs) and complementary SRRs(CSRRs). The SRR under the radiating patch, the CSRR loaded on the radiating patch, and the CSRRs on the ground of the CPW feeding reject the WiMAX, WLAN, and ITU bands, respectively. The simulation and measurement results demonstrate the performances of the proposed antenna.

Key words : UWB Antenna, SRR, CSRR, Tri-Band Notch Capability

\section{I. 서 론}

사용자가 증가함에 따라 처리해야 할 데이터가 늘어나고 그로 인해 더욱 더 향상된 성능을 갖는 무 선 통신 기술이 필요성이 대두되었다. 이러한 요구 에 대응하여 기존의 군사용 목적으로만 사용하던 Ultra Wide Band(UWB)는 2002년 Federal Communication Commission(FCC)에 의해 공식적으로 상업용으 로 승인되었고, 주요 근거리 무선 통신 기술로써 지 속적으로 연구 개발되고 있다. 이름에서도 알 수 있 듯이 $\mathrm{UWB}$ 는 $3.1 \sim 10.6 \mathrm{GHz}$ 의 넓은 주파수 대역을
포함하며, 그로 인해 높은 데이터 전송 속도, 적은 파워 소비, 멀티 패스 간섭에 강한 면역성을 가지는 이점을 갖는다. 또한, 기판 위에 비교적 쉽게 제작할 수 있으며, 그 소형 구조와 적은 단가로 많은 각광을 받고 있다. 그러나 넓은 대역에서 동작하는 초광대 역 특성으로 인해 같은 주파수 대역을 이용하는 다 른 무선 통신 기술들과 간섭이 발생하는 단점을 가 지고 있다. 대표적으로 $\operatorname{WiMAX}(3.3 \sim 3.7 \mathrm{GHz})$, WLAN (5.15 5.825 GHz), ITU(International Telecommunication Union, $8.025 \sim 8.4 \mathrm{GHz}$ )가 있다. 특히 ITU는 국 제적으로 공용으로 사용할 수 있는 주파수 대역으로

\footnotetext{
「이 논문은 2010년 정부(교육과학기술부)의 재원으로 한국연구재단의 지원을 받아 수행된 연구임(2010-0004315).」 중앙대학교 전자전기공학부(School of Electrical and Electronics Engineering, Chung-Ang University)

- Manuscript received November 25, 2011 ; Revised February 29, 2012 ; Accepted March 9, 2012. (ID No. 20111125-11S)

• Corresponding Author : Sungjoon Lim (e-mail : sungjoon@cau.ac.kr)
} 
써 인공위성을 이용한 광대역 및 차세대 통신으로 많이 활용되고 있다.

이 세 가지 무선 통신은 UWB에 비해 약 1,000 배 이상의 파워 레벨을 이용하기 때문에 해당 주파수에 서의 정상적인 동작에 방해를 일으킨다. 이와 같은 $\mathrm{UWB}$ 동작에 치명적인 간섭을 차단하기 위해 특정 대역을 저지하는 기능을 갖는 구조의 필요성이 제기 되었다 ${ }^{[1]}$.

이러한 대역 저지 특성을 갖기 위해 다양한 구조 의 장치들이 제안되었다. 그중에서도 최근 Split Ring Resonator(SRR)와 Complementary SRR(CSRR)이 대역 저지의 한 방안으로써 주목을 받고 있다. SRR은 반 대방향으로 나눠진 두 개의 금속 링으로 이루어지 며, CSRR은 SRR과 반대로 금속 위에 식각된 두 개 의 링으로 이루어진다. SRR과 CSRR은 자연상에서 일반적으로 존재하지 않는 전자기적 성질을 지니고 있는 메타 물질을 구현하기 위한 한 방법으로도 사 용되며, SRR은 음의 투자율, CSRR은 음의 유전율을 갖는다. 또한, SRR과 $\mathrm{CSRR}$ 은 $\mathrm{LC}$ 공진 성분으로 공 진 주파수에서 각각 강한 자기 커플링과 전기적 커 플링을 만들며, 신호가 전파하지 못하도록 하는 특 성을 나타낼 수 있다. 이 두 구조는 평면형으로 구현 이 가능하며, 일반적인 화학적 에칭을 통해 쉽게 제 작이 가능하다 ${ }^{[2],[3]}$. 실제로 $\mathrm{CSRR}$ 을 이용하여 특정 대역을 차단하는 UWB 안테나가 논문을 통해 다양 하게 소개되었다 ${ }^{[1],[4] \sim[6]}$. CSRR을 이용하여 하나 혹 은 두 개 이상의 대역을 차단하였으나 ${ }^{[4],[5]}$, 두 개 이 상의 다중 대역을 차단을 위해서는 CSRR 이외에도 Slot, Stub등 다양한 장치들이 함께 적용되었음을 확 인할 수 있다. 특히, Stub의 경우에는 기존의 안테나 외에도 추가적인 공간을 필요로 하기 때문에 안테나 의 크기가 커질 수 있다는 문제점을 가지고 있다 ${ }^{[1]}$.

이 같은 문제점들을 극복하기 위해 본 논문에서 는 SRR과 CSRR만을 이용하여 추가적인 공간 없이 도 삼중 대역을 차단할 수 있는 안테나를 제안하고 자 한다. 목표 대역은 앞서 설명한 WiMAX, WLAN, ITU의 세 개의 대역이며, 해당 주파수의 조정을 용 이하게 하기 위해 각 주파수에 대응하는 세 개의 장 치를 이용하였다. 본문에서는 UWB 안테나의 초기 모델과 각 $\mathrm{SRR}$ 과 $\mathrm{CSRR}$ 이 실제로 $\mathrm{UWB}$ 에 적용되는 과정을 통해 본 논문이 제안하는 삼중 대역 차단
$\mathrm{UWB}$ 안테나를 소개하고, 그 성능을 검증하였다.

\section{II. 대역 차단 능력을 갖는 UWB 안테나 설계}

\section{2-1 일반적인 UWB 모노폴 안테나}

광대역 개념이 처음 소개된 이래로, 광대역 안테 나는 다양한 목적을 위해 개발되어 왔다. 2002년 $\mathrm{FCC}$ 에 의한 $\mathrm{UWB}$ 의 상업용 승인 이후 $\mathrm{UWB}$ 기술은 주요 근거리 고속 무선 통신 기술로써 자리 잡으며 많은 주목을 받았는데, 최근의 휴대용 전자기기, 모 바일 통신 기기의 발달로 광대역 특성뿐만 아니라 안테나의 크기, 방사 특성 또한 충족시키기 위해 다 양한 형태의 안테나가 제안되었다. 그중에서도 기판 을 이용한 모노폴 안테나는 매우 간단한 구조를 가 지고 있어 제작이 쉽고 단가가 저렴하다. 또한, 이 모노폴 안테나는 전방위에 고루 방사하는 다이폴과 같은 방사 특성을 가지고 있어 모바일 통신에 이용 하기에 적합하다 ${ }^{[]}$. 널리 구현되는 전송 선로에는 마 이크로스트립 전송 선로와 Coplanar Waveguide(CPW) 전송 선로가 있다. 마이크로스트립 구조의 경우에는 기판이 결정되면 선로의 폭으로만 입력 임피던스를 조절해야 하지만, $\mathrm{CPW}$ 구조의 경우 선로의 폭과 접 지면과의 간격의 비로써 입력 임피던스가 결정되기 때문에 설계시 자유도가 높다. 따라서 본 논문에서 는 $\mathrm{CPW}$ 급전 구조를 이용하는 모노폴 안테나 형태 의 UWB 안테나를 채택하고 이용하였다.

그림 1은 본 논문에서 이용한 UWB 안테나의 구 조와 치수를 보여준다. 기판은 FR4를 이용했으며, $1.6 \mathrm{~mm}$ 의 두께와 0.035 의 loss tangent 4 의 유전율을 갖는다. 이 안테나는 오각형 모양의 방사 패치를 가 지며, 패치의 길이와 너비, 그리고 급전선으로부터 이어지는 패치 부분의 각도 $\theta$ 에 의해 그 광대역 특 성이 결정된다. 특히 패치 부분의 각도 $\theta$ 는 광대역 특성에 가장 중요한 영향을 미치는 수치로써 해당 논문에서는 66 도를 채택하였다. 그 이유는 그림 2의 각도 $\theta$ 별 반사 계수의 변화를 통해 알 수 있다. 일 반적으로 UWB 안테나의 조건을 충족시키기 위해서 는 $3.1 \sim 10.6 \mathrm{GHz}$ 의 대역에서 $10 \mathrm{~dB}$ 이상의 반사 손 실 값을 만족시켜야 하는데, 65 도 이하로 각이 작아 질 시에는 $8 \mathrm{GHz}$ 대역이 $10 \mathrm{~dB}$ 보다 작아지며 $\mathrm{UWB}$ 의 조건을 충족시키지 못하고, 67 도 이상으로 커질 


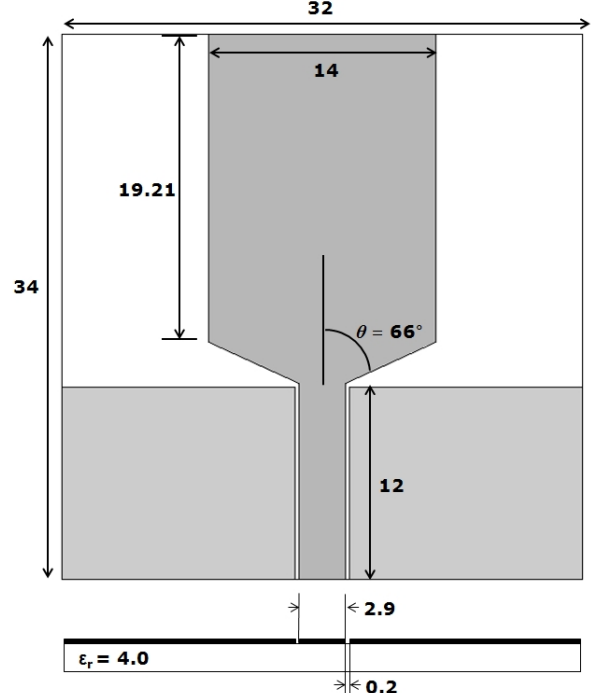

그림 1. $\mathrm{CPW}$ 급전 구조를 이용한 $\mathrm{UWB}$ 모노폴 안테나 Fig. 1. CPW fed UWB monopole antenna.

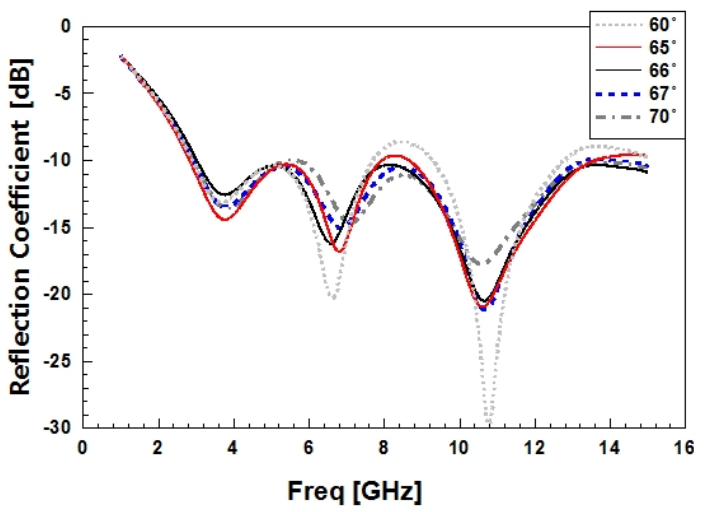

그림 2. 그림 1 의 $\theta$ 에 따른 기본적인 UWB 모노폴 안테나의 시뮬레이션 반사 계수 변화치

Fig. 2. Simulated reflection coefficients of the original UWB monopole antenna by changing $\theta$.

시에는 $\mathrm{UWB}$ 의 조건을 충족시키나, 총 대역폭이 작 아지며, 또한 반사 계수 값도 전체적으로 낮아진다. 그러므로 $\mathrm{UWB}$ 의 조건도 충족시키며 가장 넓은 대 역폭을 갖는 66도가 본 논문에서 채택한 최적의 값 이다. 그 밖의 안테나 수치는 그림 1에 표기되어 있 으며, 해당 수치들을 이용하여 기본적인 UWB 안테 나를 설계하였다.

\section{2-2 SRR과 CSRR을 이용한 대역 저지}

1960년대 러시아의 과학자 Veselago에 의해 자연
적으로 존재할 수 없는 전자기적 성질을 지니고 있 는 왼손 물질이 연구되었다만. 왼손 물질이란 특정 주파수에서 음수의 유전율과 투자율 값을 갖는 물질 로써 이러한 특징으로 인해 파장 벡터 $k$ 와 전기장 $E$, 자기장 $H$ 가 왼손의 법칙을 따르고 역방향 전파가 이 루어진다. 메타 물질이라고도 불리는 이러한 물질은 극소의 크기를 갖는 인공적인 주기구조를 이루고 있 으며, 2000년도에 최초로 Smith 박사에 의해 실험적 으로 증명되었고, SRR과 얇은 도선으로 이루어지는 메타 물질이 제안되었다 ${ }^{[9]}$. SRR은 평면 구조이며, 도선은 금속 스트립으로 대체하여 쉽게 평면형으로 구현할 수 있으며, 실제로 $\mathrm{CPW}$ 방법으로 소형화된 대역 저지 여과기의 구현이 발표된 바가 있달. $\mathrm{SRR}$ 은 음수의 투자율을 가지며 신호를 전파하지 못 하도록 하는데, 이러한 특징에 대응 관계로써 음수 의 유전율을 갖는 물질이 제안되었다. CSRR로써 명 명된 이 물질은 마이크로스트립의 접지면에 기존의 $\mathrm{SRR}$ 과 동일한 치수와 모양으로 식각하여 특정한 주 파수에서 공진을 일으키며 저지 특성을 발생시켰다 ${ }^{[3]}$. 따라서 본 논문에서는 삼중 대역 차단을 위하여 간단한 구조와 제작으로 대역 저지 특성을 만드는 $\mathrm{SRR}$ 과 CSRR을 이용하였다.

그림 3은 참고문헌 [10]에 게재된 SRR과 CSRR의 기본 구조와 등가회로 모델이다. (a)는 SRR 구조로 써, $L_{s}$ 는 링의 반지름 $r$ 과 너비 $c$ 에 의하여 결정되는 인덕턴스이고, $C_{0}$ 는 링 사이의 간격 $d$ 에 의해 결정 되는 커패시턴스 값이다. $C_{s}$ 는 직렬 커패시턴스의 값으로써 $C_{s}=C_{0} / 4$ 의 값을 갖는다. (b)는 CSRR 구 조로써 SRR과는 반대로 링의 반지름 $r$ 과 식각된 링 의 너비 $c$ 에 의해 커패시턴스 $C_{c}$ 가 결정되며, 링과 링 사이의 거리 $d$ 에 의해 인덕턴스 $L_{0}$ 가 결정된다. $\mathrm{SRR}$ 과 유사하게 $L_{c}$ 는 병렬 인덕턴스 값으로써 $L_{c}=$ $L_{0} / 4$ 으로 표현할 수 있다. 또한, 두 구조는 모두 각 각의 $L$ 과 $C$ 값을 이용하여 공진 주파수 $f_{0}=$ $(L C)^{-1 / 2} / 2 \pi$ 를 개략적으로 구할 수 있다. 만약 기 판의 두께와 손실 등의 효과를 무시하고 계산한다면 같은 치수를 갖는 SRR과 CSRR은 같은 공진 주파수 를 갖는다 ${ }^{[10]}$.

그림 4는 SRR과 CSRR을 이용하여 특정 대역 저 지 특성을 갖도록 한 UWB 안테나이다. 세 개의 안 테나는 각각 WiMAX, WLAN, ITU 대역을 차단하며, 

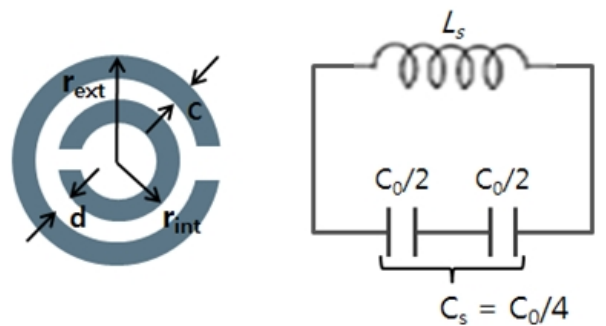

(a) $\mathrm{SRR}$ 의 기본 구조와 등가회로

(a) Structure and equivalent circuit of SRR
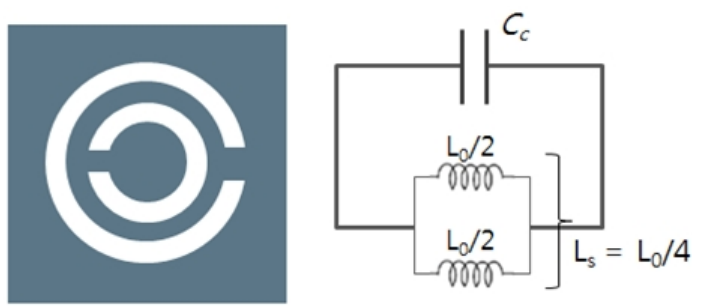

(b) CSRR의 기본 구조와 등가회로

(b) Structure and equivalent circuit of CSRR

그림 3. SRR과 CSRR의 기본 구조 및 등가회로 모델 (회색 부분이 도체를 나타냄)

Fig. 3. Equivalent circuit model and structure of SRR and CSRR(The gray part represents conductor).

초기에 설계했던 일반적인 UWB 모노폴 안테나와 같은 수치를 이용하였다. 각 CSRR과 SRR은 링의 반 지름, 링의 너비, 그리고 각 링의 갈라진 틈의 간격 으로 공진 주파수와 대역 너비를 조정할 수 있으나, 주로 바깥쪽 링의 반지름이 공진 주파수에 가장 큰 영향을 미친다. 각 장치들의 위치는 차단의 강도를 결정하는데, 급전선에 가까울수록 그 차단 정도가 강해진다. 각 $\mathrm{CSRR}$ 과 SRR은 목표하는 주파수 대역 을 차단하기 위해 크기를 조정하였으며, 그 수치 정 보는 그림에 나와 있다. (a)는 바닥면에 SRR을 로딩 하여 안테나 패치면과 자기적 커플링을 발생시키고, 자기적 $\mathrm{LC}$ 공진으로 원하는 주파수 대역을 차단하 는 구조이다. SRR의 반지름을 충분히 늘려 가장 낮 은 $3 \mathrm{GHz}$ 의 대역의 WiMAX를 차단시켰다. (b)와 (c) 는 각각 방사 패치면, 접지면에 CSRR을 식각하여 전기적 $\mathrm{LC}$ 공진을 이용하여 특정 주파수 대역을 차 단하는 구조이다. (b)는 $5 \mathrm{GHz}$ 대역의 WLAN, (c)는 $8 \mathrm{GHz}$ 대역의 ITU를 차단한다. 이 세 개의 안테나는 각각 해당하는 주파수만을 차단하는 구조이다. 따라 서 각 저지 대역의 주파수를 바꿀 시에 해당하는

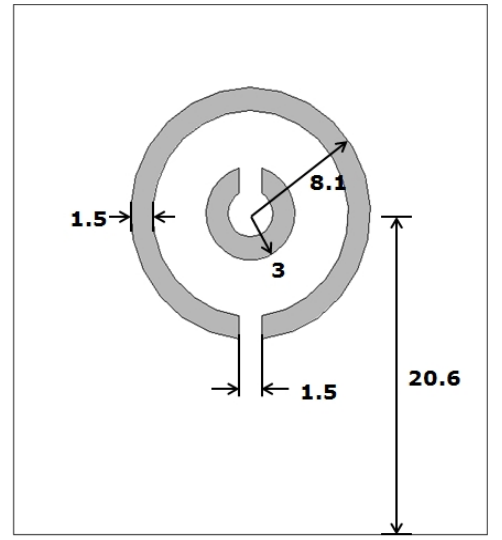

(a) WiMAX band가 차단된 안테나

(a) UWB antenna rejecting WiMAX band

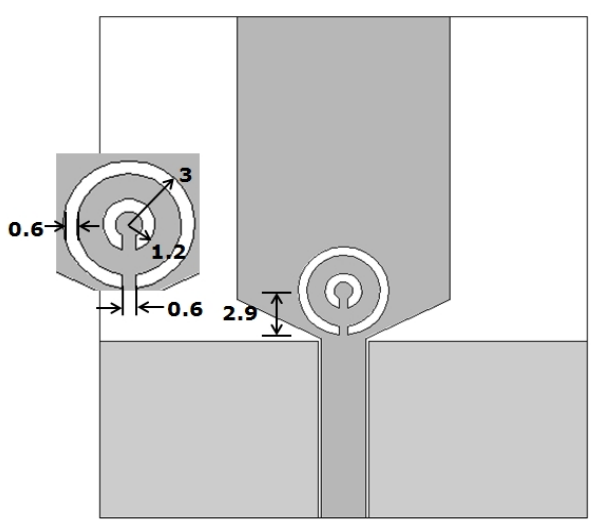

(b) WLAN band가 차단된 안테나

(b) UWB antenna rejecting WLAN band

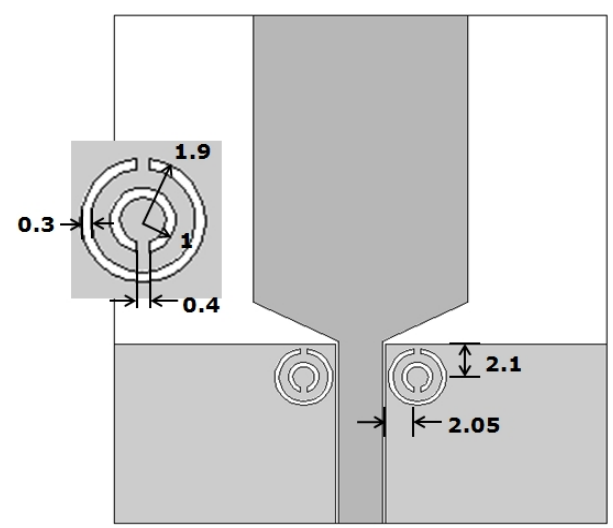

(c) ITU band가 차단된 안테나

(c) UWB antenna rejecting ITU band

그림 4. (a) WiMAX, (b) WLAN, (c) ITU 대역을 차단하 는 특성을 갖는 UWB 안테나의 3 가지 구조

Fig. 4. UWB antennas rejecting (a) WiMAX band, (b) WLAN band, and (c) ITU band. 


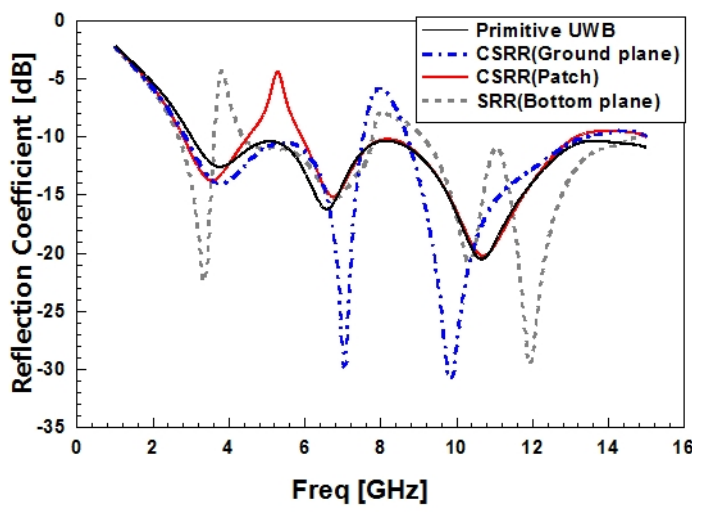

그림 5. 특정 대역을 차단하는 UWB 안테나의 반사 계수 시뮬레이션 그래프

Fig. 5. Simulated reflection coefficients of the notched UWB antenna.

$\mathrm{SRR}$ 혹은 $\mathrm{CSRR}$ 의 수치를 조정하면 되므로 설계하 기에 용이하다. 그림 5 는 일반적인 UWB 안테나와 비교한 세 개의 대역 차단 안테나의 반사 계수 시뮬 레이션 값이다. 이 그래프를 통해 각 장치마다 해당 하는 주파수를 독립적으로 차단하는 것을 확인할 수 있다. 다만 SRR 구조의 경우, 3 중 대역을 차단하는 것처럼 보인다. 이는 고조파 성분으로써 주파수를 독립적으로 조정하기 어렵고 차단되는 정도가 낮으 며 조정 또한 어렵다.

\section{III. 제안된 안테나의 제작, 측정 결과 및 논의}

그림 6은 본 논문에서 제안하는 세 가지 구조가 혼합된 UWB 안테나의 실제 제작된 원형 모델이며, 그림 7은 제안된 안테나의 VSWR 결과 값이다. 측정 에는 HP 8510C Network Analyzer를 이용하였고, EM 시뮬레이션 결과와 비교하여 도시하였다. 그림 7을 통해 제안된 안테나는 $3.1 \sim 10.6 \mathrm{GHz}$ 에서 2 이하의 VSWR 값을 갖는 정상적인 UWB 안테나이며, 일반 적인 UWB 안테나와 비교하여 삼중 대역 차단 능력 을 갖고 있음을 명백하게 확인할 수 있다. 또한, 각 세 가지 구조에서 차단되었던 주파수 대역이 제안된 안테나에서 그대로 차단된 것을 통해 혼합된 구조에 서도 각 장치가 정상적으로 동작함을 확인할 수 있 다. 다만 세 개의 구조가 혼합되면서 접지면에 식각 된 $\mathrm{CSRR}$ 은 패치면의 CSRR과 바닥면의 SRR과 독립 적으로 동작하지만, 바닥면의 SRR은 패치면과 자기

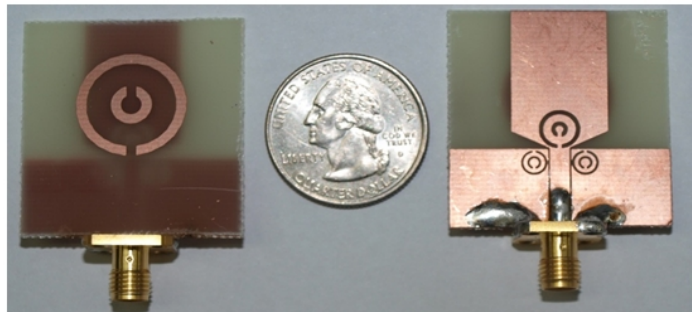

그림 6. 실제 제작된 삼중 대역이 차단된 UWB 안테 나의 원형 모델

Fig. 6. Fabricated prototype model of the tri-band notched UWB antenna.

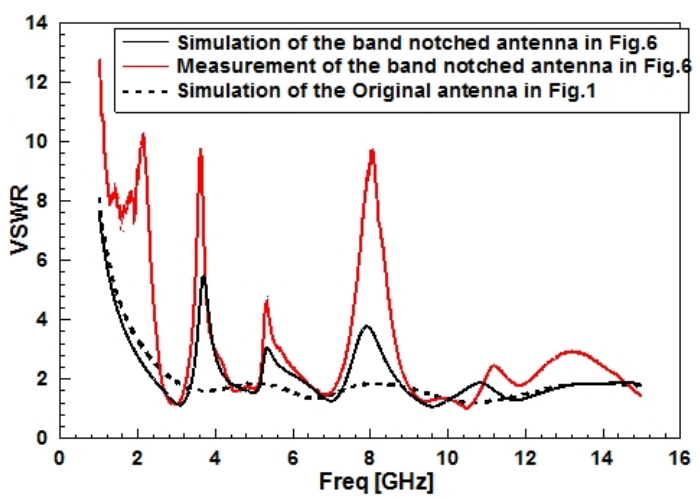

그림 7. 제안된 안테나의 VSWR 시뮬레이션 및 측정값

Fig. 7. Simulated and measured VSWR of the proposed antenna.

적 커플링을 통해 동작하기 때문에, 패치면의 CSRR 과 간섭이 발생한다. 시뮬레이션으로 비교했을 때 세 개의 구조의 혼합 전에 $3.6 \sim 4.31 \mathrm{GHz}, 4.78 \sim 6.07$ $\mathrm{GHz}$ 에서 동작하던 WiMAX, WLAN 대역이 혼합 후 $3.4 \sim 4.28 \mathrm{GHz}, 5.18 \sim 6.17 \mathrm{GHz}$ 로 주파수가 다수 높 아지게 되었다. 시뮬레이션 값과 실제 측정값은 매 우 유사한 결과를 가지고 있으나, 실제로 측정값이 더 우수한 차단 능력을 가지는데, 이는 안테나의 개 량에 따라 더욱 향상된 결과를 얻을 수 가능성을 나 타낸다.

제안된 안테나가 실제로 모노폴 안테나로써 동작 하는지 확인하기 위해 그림 8는 본 안테나가 UWB 모노폴 안테나로써 동작하는 $3.2,4.5,6 \mathrm{GHz}$ 에서 측 정된 방사 패턴을 보여준다. 시뮬레이션과 비교했을 때 다소 적은 이득 값을 나타내지만, H-plane에서 전 방위로 고루 방사하는 패턴, E-plane에서는 호리병 모양의 방사 패턴을 가짐으로써 모노폴 안테나로 정 

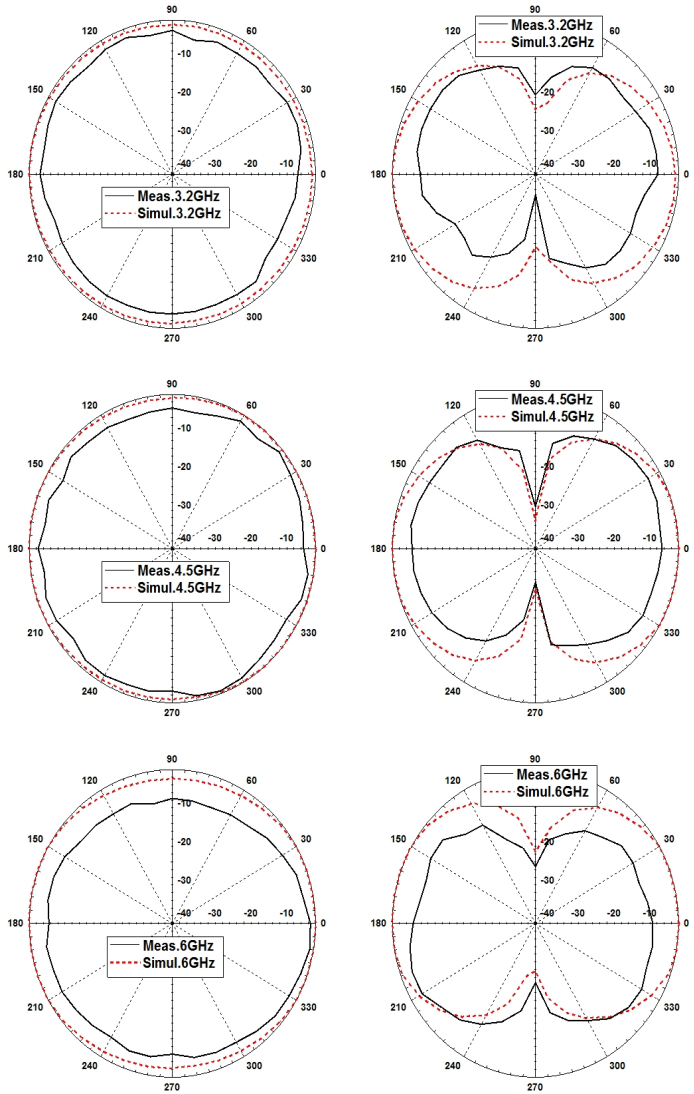

(a) H-plane

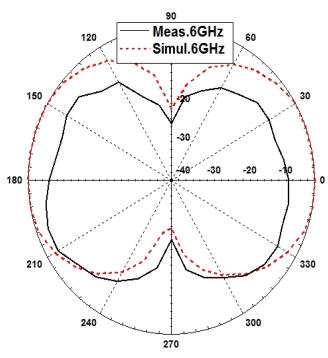

(b) E-plane

그림 8. 제안된 안테나의 측정된 방사 패턴

Fig. 8. Measured radiation patterns of the proposed antenna.

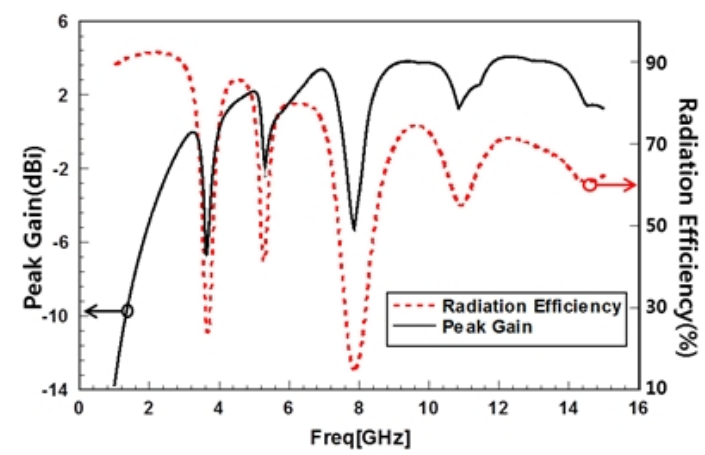

그림 9. 제안된 안테나의 최고 이득 및 방사 효율 시 뮬레이션

Fig. 9. Simulated peak gain and radiation efficiency of the proposed antenna.

상적으로 동작함을 확인할 수 있다.

그림 9은 제안된 안테나의 최고 이득과 방사 효율

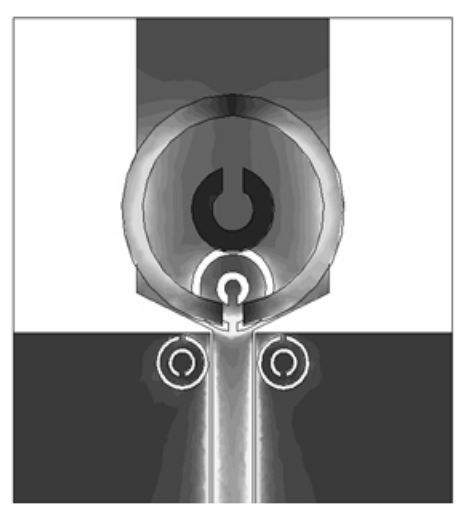

(a) WiMAX band(3.7 GHz)

$\mathrm{OA} / \mathrm{m}$

100

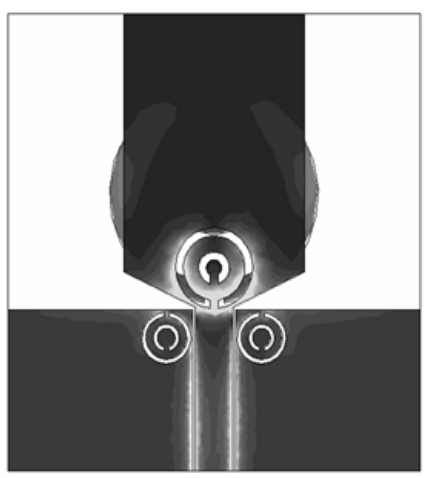

(a) WLAN band $(5.3 \mathrm{GHz})$

$0 \mathrm{~A} / \mathrm{m}$

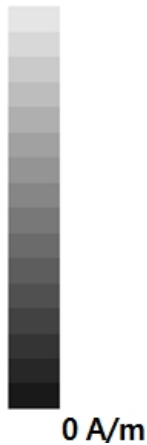

100
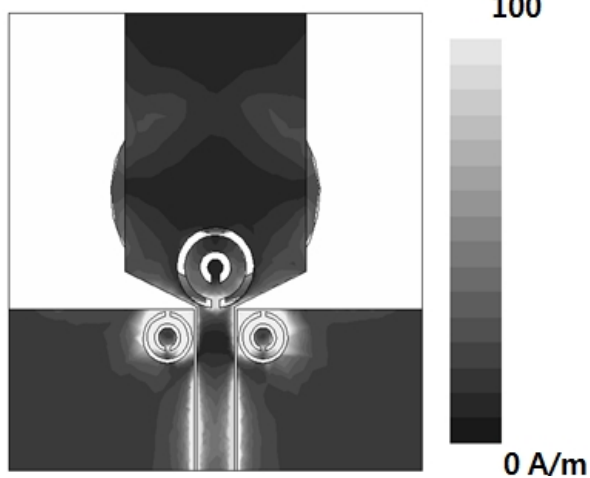

(a) ITU band $(8.1 \mathrm{GHz})$

그림 10. 제안된 안테나의 저지 대역에서 전류 밀도 크기

Fig. 10. Current density of the proposed antenna at the rejected band.

의 시뮬레이션 값을 보여준다. 그림을 통해 최고 이 득과 방사 효율 모두 저지 대역에서 현저하게 감소 함을 확인할 수 있다. 이는 본 안테나가 저지 대역에 서는 정상적으로 동작하지 않으며, 대역 차단 능력 
이 효과적으로 수행되고 있음을 확인시켜 준다. 또 한, 저지 대역 외 영역에서는 $70 \%$ 이상의 방사 효 율을 가짐으로써 정상적으로 안테나로써 동작함을 알 수 있다.

그림 10 은 제안된 안테나의 전류 밀도 크기이다. WiMAX 대역인 $3.7 \mathrm{GHz}$ 에서는 바닥면의 SRR에 전 류 밀도가 강하게 분포하였으며, WLAN 대역인 5.3 $\mathrm{GHz}$ 에서는 패치면의 CSRR, 그리고 ITU 대역의 8.1 $\mathrm{GHz}$ 에서는 접지면의 두 개의 $\mathrm{CSRR}$ 에 가장 강하게 전류 밀도가 분포함을 확인할 수 있다. 각 저지 대역 주파수에서 해당하는 장치에 전류 밀도가 가장 강하 게 분포하는 것을 통해 각 장치들이 해당 대역을 효 과적으로 차단하고 있음을 알 수 있다.

그림 11 은 제안된 안테나의 군지연 특성이다. 군 지연 특성은 UWB 안테나의 매우 중요한 수치로 신 호 왜곡 정도와 위상 선형성을 나타내는 척도이다. 제안된 안테나를 각각 송신 및 수신 안테나로 사용 하여 측정하였으며, 2개의 안테나가 서로 정면을 향 하게 배치하였을 때 결과가 그림 11(a)에 도시되었 으며, 서로 측면을 향하게 배치하였을 때 결과는 그 림 11(b)에 도시되었다. 네트워크 분석기로 측정하였 기 때문에, 원거리 조건에서는 충분한 RF 전력을 송 수신할 수 없으므로 $15 \mathrm{~cm}$ 의 간격을 두고 2 개의 안 테나를 배치하였다 ${ }^{[1]}$. 제안된 안테나의 군지역 변화 량은 차단 대역과 몇몇 특정 대역을 제외한 전 동작 대역에서 $1 \mathrm{~ns}$ 를 넘어서지 않고 정상적으로 동작함 을 확인할 수 있었다. 초광대역 안테나의 경우, 안테 나의 배치 형태에 따라 그 특성이 변화할 수 있는데

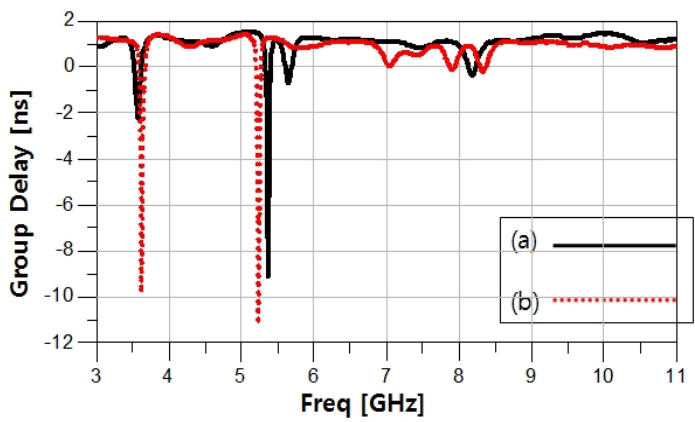

그림 11. 제안된 안테나를 송수신부에 (a) 정면과 정 면으로 배치했을 때와 (b) 측면과 측면으로 배치했을 때 군지연 특성

Fig. 11. The group delay of the proposed antenna oriented in (a) front-to-front and (b) side-by-side.
[12],[13], 약 $7 \mathrm{GHz}$ 대역에서는 측면 배치 시 군지연 특 성이 다소 나빠지지만, 정면 배치의 경우에서는 정 상적으로 동작하는 것을 확인하였다.

\section{IV. 결 론}

본 논문에서는 오직 $\mathrm{SRR}$ 과 $\mathrm{CSRR}$ 만으로 삼중 대 역을 차단하는 UWB 안테나를 설계하고, 측정, 분석 하였다. CPW 급전 구조로 비게 되는 바닥면에 SRR 을 이용하는 구조를 제시하여 추가적인 공간 없이 새로운 차단 대역을 생성하였으며, 기존의 CSRR 적 재 방식과 혼합하여 SRR과 CSRR 모두를 이용하여 다중 대역이 차단되는 안테나를 제안하였다. 제안된 안테나는 WiMAX, WLAN, ITU 세 가지 대역에서 차 단 능력을 가지며, VSWR, 안테나 이득 및 방사 효 율, 그리고 전류 밀도 등을 통해 각 장치가 해당되는 주파수 대역을 효과적으로 차단하고 있음을 확인하 였다. 따라서 본 논문에서 얻은 결과는 다중 대역 차 단 능력이 필요한 UWB 시스템에 다양하게 응용될 수 있을 것이다.

\section{참 고 문 헌}

[1] D. -O. Kim, C. -Y. Kim, "CPW-fed ultra-wideband antenna with triple-band notch function", Electron. Lett., vol. 46, no. 18, pp. 1246-1248, Sep. 2010.

[2] F. Martin, F. Falcone, J. Bonache, T. Lopetegi, R. Marques, and M. Sorolla, "Miniaturized coplanar waveguide stopband filters based on multiple tuned split ring resonators", IEEE Microw. Wireless Compon. Lett., vol. 13, no. 12, pp. 511-513, Dec. 2003.

[3] F. Falcone, T. Lopetegi, J. D. Baena, R. Marques, F. Martin, and M. Sorolla, "Effective negative- $\varepsilon$ stopband microstrip lines based on complementary split ring resonator", IEEE, Microw. Wireless Compon. Lett., vol. 14, no. 6, pp. 280-282, Jun. 2004.

[4] J. Liu, S. Gong, Y. Xu, X. Zhang, C. Feng, and N. Qi, "Compact printed ultra-wideband monopole antenna with dual band-notched characteristics", Electron. Lett., vol. 44, no. 12, pp. 710-711, Jun. 2008.

[5] L. Li, Z. -L. Zhou, J. -S. Hong, and B. -Z. Wang, "Compact dual-band-notched UWB planar monopole 
antenna with modified SRR", Electron. Lett., vol. 47, no. 17, pp. 950-951, Aug. 2011.

[6] D. -O. Kim, N. -I Jo, H. -A. Jang, and C. -Y. Kim, "Design of the ultrawideband antenna with a quadruple-band rejection characteristics using a combination of the complementary split ring resonators", PIER, vol. 112, pp. 93-107, Jan. 2011.

[7] I. Minin, Microwave and Milimeter Wave Technologies: Modern UWB Antennas and Equipment, In-Tec., pp. 19-48, 2010.

[8] V. G. Veselago, "The electrodynamics of substances with simultaneously negative values of $\varepsilon$ and $\mu "$, Sov. Phys.-Usp., vol. 10, pp. 509-514, 1968.

[9] D. R. Smith, W. J. Padilla, D. C. Vier, S. C. NematNasser, and S. Schultz, "Composite medium with simultaneously negative permeability and permittivity", Phys. Rev. Lett., vol. 84, pp. 4184-4187, 2000.

[10] J. D. Baena, J. Bonache, F. Martin, R. M. Sillero, F. Falcone, T. Lopetegi, M. A. G. Laso, J. G-Garcia, I. Gil, M. F. Portillo, and M. Sorolla, "Equi-

\section{유 민 영}

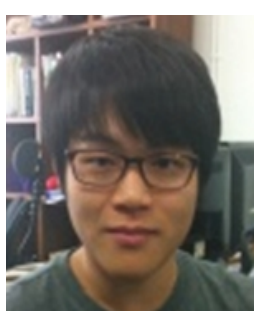

2006년 3월 현재: 중앙대학교 전 자전기공학부 학부과정

[주 관심분야] Metamaterial, UWB 안테나 valent-circuit models for split ring resonators and complementary split-ring resonators coupled to planar transmission lines", IEEE Trans. on Microw. Theory and Techniq., vol. 53, no. 4, pp. 14511461, Apr. 2005.

[11] Y. Cho, K. Kim, D. Choi, S. Lee, and S. Park, "A miniature UWB planar monopole antenna with 5$\mathrm{GHz}$ band-rejection filter and the time-domain characteristics", IEEE Trans. on Antennas and Propagation, vol. 54, no. 5, pp. 1453-1460, May 2006.

[12] Y. D. Dong, W. Hong, Z. Q. Kuai, and J. X. Chen, "Analysis of planar ultrawideband antennas with on-ground slot band-notched structures", IEEE Trans. on Antennas and Propagation, vol. 57, no. 7, pp. 1886-1893, Jul. 2009.

[13] T. G. Ma, S. J. Wu, "Ultrawideband band-notched folded strip monopole antenna", IEEE Trans. on Antennas and Propagation, vol. 55, no. 9, pp. 24732479, Sep. 2007.
임 성 준

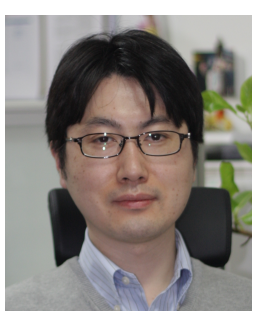

2002년 2월: 연세대학교 전자공학 과 (공학사)

2004년 2월: University of California Los Angeles 전기공학과 (공학석 사)

2006년 2월: University of California Los Angeles 전기공학과 (공학박 사)

2006년 2007년: University of California, Irvine Post-Doc. 2007년 3월 현재: 중앙대학교 전자전기공학부 조교수

[주 관심분야] 마이크로파 회로 및 안테나 